\title{
MULTIMODALITY IN NATURAL SCIENCE EDUCATION
}

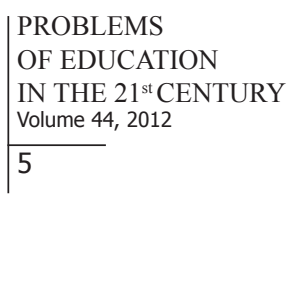

Natural Science Education plays a very important role in broadening students' world outlook. The Natural Science classes should discuss real, concrete things and phenomena, which are a part of students' reality and even everyday life (Lamanauskas, 2003).

Nowadays it is necessary to take advantage of the Information and Communication Technologies to support innovative methodologies of teaching natural science. As well, it leads to different ways of seeing the world and consequently leads to different beliefs concerning our comprehension of the world. Expanding the experiences as the augmented reality, it is real now. So, words and terms which are used acquire meaning in the contexts where they are used. The relevant perspective within a sector is decisive for how a question, a problem, a statement is to be interpreted, what is interesting, pertinent an objective (Arroio, 2011).

The multimodal phenomena (multimodal texts, web sites, audiovisuals, three-dimensional objects, simulations, animations and events) are constructed from the integration of the abstract means, of the non-material resources, such as language, symbol, image, sound, architecture and environment. These phenomena expand the cognitive sense when they are integrated by the sensory modalities with their visual, tactile, olfactory, gustatory, auditory and kinesthetic characteristics and they in general are called semiotic resources. In this sense, meaning making in the natural science classroom is produced through the articulated use of different semiotic modes (verbal, gestural, visual etc.) (Kress, Ogborn \& Martins, 1998).

The means are the ways through which multimodal phenomena are materialized such as printed materials, phenomenon scheme written in chalk on a blackboard, holding of an event, television, computer, photo camera, movie camera, data show or other any material object (Arroio, 2011; Dicks, et al., 2006; O'Halloran, 2008; O'Halloran, 2011).

In this perspective for Lemke $(1992,1998)$, the construction of meaning in the Natural Science classroom is not just produced through the words that are said, but also by the diagrams that are drawn and the formulae that are written down, and the experiments that are done by students and teachers. Personal construction of knowledge occurs through the interaction between the individual's knowledge schemes and his or her experiences with the environment. Science education must encourage the development of creative thinking (Laius, \& Rannikmäe, 2005).

Nowadays, visualizations are a part of scientific practice that could influence science education (Linn, 2003). This author argues that visualizations can help experts to test new ideas and reveal certain aspects of scientific phenomena displaying new insights and allow comparisons with different scenarios. But, visualizations are also important to students. Visualizations can illustrate an idea that words cannot describe and in the same way can introduce students to important aspects of scientific research that are frequently neglected in science education.

Learning science is related to participating in activities, which offer a scientific way of thinking and acting. But this is not easy and perhaps not even possible in a traditional school context because it is expected that students must cross over certain discursive and linguistic borders. 
PROBLEMS

OF EDUCATION

IN THE $21^{\text {st }}$ CENTURY

Volume 44, 2012

In Natural Sciences, in addition to the concepts involving qualitative aspects, students are challenged in their learning to use, among others, mathematical knowledge that will assist them in the organization, interpretation and resolution of quantitative aspects. This requires from students the intellectual transit through various forms of languages and representations, constituting what it is called 'multimodality'.

These considerations would imply that the language used by the teacher and students should not be expected to be the same, and the use of different semiotic modes would not play the same role in the teaching and learning of an abstract scientific concept (Márquez, Izquierdo, \& Espinet, 2006). It should be considered that when student use a different mode that not just a word they are negotiating the meanings with their own perceptions, teacher expectations, school-scientific concepts and other factors.

Student's texts can thus be analysed as traces of the choices made by them from the resources which were available to them, which they saw as pertinent at the moment of choice, in conformity with their interests vis- 'a-vis the topic. The transformations which link their text to the text that constitutes the original resources are then the evidence of the work they engaged in, constantly guided by their interest. (Jewitt, Kress, Ogborn, \& Tsatsarelis, 2001, pp. 129-130)

In this perspective it is introduced the idea of learning mediated by multimodality that has its definition anchored in the one of multimedia learning (Mayer, 2005), about which we suggest the amplification by the insertion of other resources such as educational games, with or without the use of computers.

According to Mayer:

The multimedia learning is defined as the learning from words (spoken or printed) and figures (illustrations, photos, maps, graphics, animations or videos) (2005, p. ix).

And for Jewitt:

[...] There is now an increasing understanding that occasions of communication always draw on a multiplicity of modes of communication at the same time. When we speak we also make facial expressions, we gesture, stand at a certain distance, and so on, all of which makes meaning together. This ensemble of modes we regard as the normal condition of communication and we refer to that as multimodal communication or as multimodality (Jewitt et al., 2001, p. 6).

Learning mediated by multimodality is conceptualized as the one that is favoured by the practice of the multiplicity expression's forms of school and scientific principles, or principles of Science, Technology, Society and Environment (STSE), in which there is the transit between manual or concrete activities (experiments, games or artefacts, computer-mediated or not), the word (spoken or printed) and the images (illustration, photo, map, chart, graph, equation, animation, video etc.).

Another aspect that seems to have an enormous relevance in the perspective of multimodal learning are the practices established by the institution 'school', which generate its culture.

This leads us to interpret the school culture with a focus on the practices of production and attribution of the meanings through language, i.e., culture as a sharing of meanings.

When a group shares a culture, it shares a set of meanings, constructed, taught and learned in the practices of language use. The word 'culture'implies, therefore, the set of practices through which the meanings are produced and shared in a group. They are the arrangements 
and the relationships involved in an event that start, predominantly, to crave attention from those who analyze the culture based on this perspective, which can be summed up in the idea that culture represents a set of significant practices (Moreira \& Candau, 2007, p.27).

In other words, the practice of multimodality cannot disconsider that students, in a first moment, will use the learning offered by the school throughout their schooling process, which will probably cause them to build their replicas with those meanings which seem more pertinent at the moment of its production, as a rule through the fragmented Cartesian perspective.

A fundamental aspect of multimodality and that receives influence from school culture is the explicit expression of textual and imagetic coherence in its products, because we consider this coherence as fundamental evidence of the multimodal understanding and, as a result, of the systemic learning.

The question of multimodality in the perspective of the multiplicity of representations and of narrative forms in Natural Science has been the object of attention of the academic community and called 'third wave of scientific literacy' (Klein \& Kirkpatrick, 2010).

The initial focus of scientific literacy centered efforts on writing across the curriculum; the subsequent focus that more directly involves the area of Natural Science has concentrated efforts in the recognition of the forms of writing and of the reasoning of particular interest to the Natural Science. This second focus was represented by the production of speech genres, such as protocols, reports, pre-reports and arguments (Dias de Souza, 2010) and the third focus began with attention on the role of graphics and other forms of representation in Natural Science and at the same time paved the way for the study of the role that the internet plays in the representations to which students have access (Klein \& Kirkpatrick, 2010).

This means that the student must be initiated in the mastery and incorporation of an extensive symbolic language of the Natural Sciences and Mathematics area, of a big set of mathematical operations, of conceptual aspects, of the interrelation between the elements of this set, the organization of textual and imagetic coherence and the tools of technology.

Learning Natural Sciences, therefore, involves being initiated into the ideas and practices of the community and it is still necessary to make these ideas and practices meaningful at an individual level (Driver et al., 1998), in addition to the fundamental and essential school organizational structure and to the active participation of the initiate.

In school terms the initiation into the world of Natural Sciences is in charge of him who leads the process of initiation, i.e., the natural science teacher, spreading the symbology and its interrelationships through the work with the language and organizing the process by which individuals generate meanings.

The interpretative work of students is reshaped through their engagement with a range of modes, image, animation, hypertext, and layered multimodal texts. In such a view, students need to learn how to recognize what is salient in a complex multimodal text, how to read across the modal elements in a textbook or IWB, how to move from the representation of a phenomenon in an animation to a static image or written paragraph, and how to navigate through the multiple paths of a text. These complex tasks-as against traditional taxonomies of print skills-are central to multimodal learning and development. Learning increasingly involves students in working across different sites of expression, negotiating and creating new flexible spaces for planning, thinking, hypothesizing, testing, designing, and realizing ideas (Jewitt, 2006).

The school must provide the appropriate infrastructure conditions and at the same time must partake this process in its fullness with the apprentice, breaking cultural paradigms, assuming its protagonism and interacting in a diligent and enterprising way.

Assuming that the adopted conception of teaching stipulates that students should be 
PROBLEMS

OF EDUCATION

IN THE $21^{\text {st }}$ CENTURY

Volume 44, 2012

immersed in the conventional ideas of science. The role of the teacher providing experimental evidences and providing the tools and cultural conventions didactic from the practices of the scientific community gains central importance in this process.

Driver et al. (1998) mark a particular challenge in this process: to obtain the answer(s) to the question 'How to successfully achieve this process of enculturation in the routine of ordinary classroom?'

Thus deserve attention from researchers and natural science teachers when constructing symbiotic teaching sequences that involve the use of multimodal phenomena, associated to qualitative concepts and interpretations or solutions of quantitative problems, interpenetrating the various representative forms of languages, as an alternative proposal that contributes toward the overall success in the process of scientific enculturation.

In a previous study (Dias de Souza, 2010) it was recognized the possibility of the practice of epistemic operations (Jiménez, 2009, p.9) for the exercise of multimodality, as a contribution to the learning process in Natural Science, starting from the assumption that the learning in this area is an interdisciplinary field of research from the disciplinary perspectives of psychology, anthropology, micro sociology, applied linguistics, neurosciences and computer science (Bricker \& Bell, 2008, p. 485).

In this perspective Klein and Kirkpatrick adopt a vision of learning in which learning in Natural Science is "the recognition/mapping of the connections between the concepts of the science, its representations and the perceptual experiences" (2010 p. 88), that we expand adding the time factor, i.e., the recognition/mapping must persist in the long-term memory.

As teachers and researchers we recognize that the design of the lesson must be adapted to the experience, to the prior knowledge and to the student's interest, as well as to the level of the interactivity, sequencing and stimulus that the use of technology, experimentation or games can promote, influencing the efficiency and effectiveness of learning.

The competence of transitions between the different representative levels is an essential tool for a full assessment of the natural phenomena. The acquisition of this ability is a big challenge that still exists at the teaching-learning of natural sciences, since this kind of work involves representation and visualization skills. In the school, the teacher is the responsible for introductions of activities using visual tools and, thus, his practice will determine the student capacity to understand, see and move between the representative levels in different modes

This perspective to the use of multimodality in the classroom leads us to seek answers to certain questions such as:

What is the level of acceptance of the proposal by the students?

What were the opportunities that students had in their scholarship to apply the multimodality of forms of representation in a single object of study?

What is the degree that students demonstrate at the final product (activity report) of the expression of the multiplicity of principles of a thematic content?

What degree of coherence between the multiplicity of forms of language is presented in the final product (activity report)?

These questions are central in research works that find in multimodality a fertile field to expand the studies of the teaching-learning process.

\section{References}

Arroio, A. (2011). Is the natural science teacher education programs enough for a contemporary society. Problems of Education in the $21^{\text {st }}$ Century, 37, 5-8.

Arroio, A. (2012). "Ciências da Natureza", texto didático produzido para a disciplina Ciências da Natureza e suas Tecnologias do Curso Gestão de Currículo para Coordenadores, Programa REDEFOR, SEE/USP, São Paulo: 2011/2012 (www.redefor.usp.br, retrieved in 03/02/2012). 
Bricker, L. A., Bell, P. (2008). Conceptualizations of argumentation from science studies and the learning sciences and their implications for the practices of science education. Science Education, 92 (3) 473-498.

Dias de Souza, D. D. (2010). Sobre a mediação de um material instrucional na aprendizagem de estudantes em aulas de química: gêneros do discurso e argumento. 140 f. Dissertação (dissertation in Science Education) - Faculdade de Educação, Universidade de São Paulo, São Paulo, 2010.

Dicks, B., Soyinka, B., Coffey, A. (2006). Multimodal ethnography. Qualitative Research, 6 (1) 77-96.

Driver, R., Asoko, H., Leach, J., Mortimer, E., Scott, P. (1994). Constructing scientific knowledge in the classroom. Educational Researcher, 23, 5-12.

Jewitt, C. (2006). Technology, literacy and learning: A multimodal approach. London: Routledge.

Jewitt, C., Kress, G., Ogborn, J., Tsatsarelis, C. (2001). Exploring learning through visual, actional and linguistic communication: The multimodal environment of a science classroom. Educational Review, 53 (1), 5-18.

Jiménez, M. P. A. (2005). A argumentação sobre questões sócio-científicas: Processos de construção e justificação do conhecimento em sala de aula. In: Encontro Nacional De Pesquisa em Educação em Ciências. Proceedings V ENPEC, Bauru, 1-12.

Kress, G., Ogborn, J., Martins, I. (1998). A satellite view of language: Some lessons from science classrooms. Language Awareness, 7 (2 \& 3) 69-89.

Laius, A., Rannikmäe, M. (2005). The influence of social issue-based in science teaching on students' creative thinking. Science Education International, 16 (4) 281-289.

Lamanauskas, V. (2003). Natural Science Education in Contemporary School. Siauliai: Siauliai University Press, $514 \mathrm{p}$.

Lemke, J. L. (1992). Intertextuality and educational research. Linguistic and Education, 4, 257-267.

Lemke, J. L. (1998). Teaching all the languages of science: Words, symbols, images and actions. Retrieved May 12, 2012, from http://academic.brooklyn.cuny.edu/education/jlemke/papers/barcelon.htm

Linn, M. (2003). Technology and science education: Starting points, research programs, and trends. International Journal of Science Education, 25 (6) 727-758.

Márquez, C., Izquierdo, M., Espinet, M. (2006). Multimodal science teachers' discourse in modelling the water cycle. Science Education, 90, 202-226.

Mayer, R. E. (2005). Cambridge handbook of multimedia learning. New York: Cambridge University Press. 663p.

Moreira, A. F. B., Candau, V. M. (2003). Educação escolar e cultura(s): construindo caminhos. Revista Brasileira de Educação, 23, 156-168.

Oee Halloran, K. L. (2011). Multimodal Discourse Analysis. In K. Hyland and B. Partridge (Eds) Companion to Discourse. London and New York: Continuum.

O'e Halloran, K. L. (2008). Systemic functional-multimodal discourse analysis (SF-MDA): constructing ideational meaning using language and visual imagery. Visual Communication, 7 (4), 443-475.

Klein, P. D., Kirkpatrick, L. C. (2010). Multimodal literacies in Science: Currency, Coherence and Focus. Research in Science Education, 40 (1), 87-92.

Received: May 12, 2012

Accepted: June 20, 2012

\begin{tabular}{|ll|}
\hline Agnaldo Arroio & $\begin{array}{l}\text { Doctor, Professor, Faculty of Education, University of São Paulo, São Paulo, } \\
\text { Brazil. } \\
\text { E-mail: agnaldoarroio@yahoo.com } \\
\text { Website: http://www.fe.usp.br }\end{array}$ \\
& PhD in Education, Faculty of Education, University of São Paulo, São Paulo, \\
Dirceu D. D. de Souza & E-mail: baumcima@yahoo.com.br \\
& Website: http://www.fe.usp.br \\
\hline
\end{tabular}

